
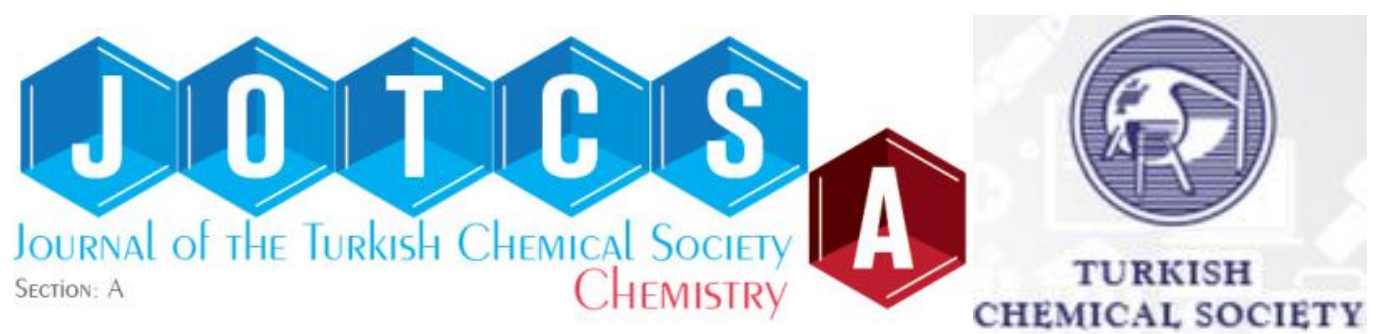

\title{
A Green and Efficient Method for the Synthesis of 3,4- Dihydropyrano[c]chromene using Phosphate Fertilizers (MAP, DAP and TSP) as Heterogeneous Catalysts
}

\author{
Soukaina CHEHAB 1 (D), Youssef MERROUN 1 ,

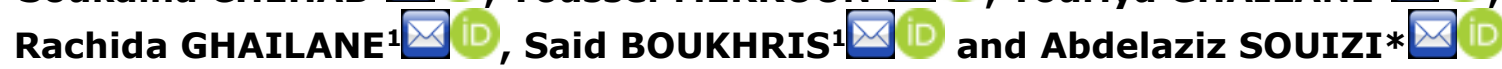

Laboratory of Organic, Organometallic and Theoretical Chemistry, University of Ibn Tofail, Faculty of Science, B.P. 133, 14000 Kenitra, Morocco

\begin{abstract}
This article presents a simple and green method for the synthesis of 3,4dihydropyrano[c]chromenes, they have been obtained by the condensation of an aromatic aldehyde, malononitrile and 4-hydroxycoumarin in presence of phosphate fertilizers (Monoammonium phosphate MAP, Diammonium phosphate DAP and Triple superphosphate TSP) as heterogeneous catalysts and ethanol as an ecological solvent. This method has remarkable advantages, such as excellent catalytic performance of the catalysts used in the ethanol and the facility of preparation of the desired products with high to excellent yields (>92\%) in short reaction times varying from 30 to 45 min, the long-term durability and easy recovery of catalysts, constitute a good heterogeneous system. All these advantages added to the low cost of these catalysts and their ecological profile have allowed them to be an alternative to the other synthetic and toxic catalysts used previously.
\end{abstract}

Keywords: Heterogeneous catalysts, MAP, DAP, TSP, 3,4-dihydropyrano[c]chromene, phosphate fertilizers.

Submitted: November 28, 2018. Accepted: January 23, 2018

Cite this: Chehab S, Merroun Y, Ghailane T, Ghailane R, Boukhris S, Souizi A. A Green and Efficient Method for the Synthesis of 3,4-Dihydropyrano[c]chromene using Phosphate Fertilizers (MAP, DAP and TSP) as Heterogeneous Catalysts. JOTCSA. 2018;5(2):355-70.

DOI: http://dx.doi.org/10.18596/jotcsa.358609.

*Corresponding author. E-mail: souizi@yahoo.com 


\section{INTRODUCTION}

Awareness of the harmful effects of certain practices used in chemical synthesis and the need to protect the environment was the reason why research in the chemical area was directed for developing some synthesis strategies that are environmentally friendly (1-2). Consequently, the main aim of chemists is to find the procedures of synthesis using different kinds of catalysts to reduce the cost and time of reaction with good yields of desired products (3). Indeed, the use of heterogeneous phosphate-based catalysts takes great importance in chemical synthesis due to their availability essentially in Morocco which is considered as the most known country in the production of natural phosphate (4-9). Other heterogeneous catalysts as hydroxyapatite (10-13) and fluoroapatite (14-16) are also used in organic synthesis. In particular our work is aimed to 3,4dihydropyrano[c]chromene synthesis, which gains a lot of attention due to their various biological activities (17-22), they are well known as spasmolytic, diuretic, anticoagulant, anti-cancer and anti-anaphylactic, they can also be used as cognitive enhancers, for the treatment of neurodegenerative diseases, including Alzheimer's disease, amyotrophic lateral sclerosis, Huntington's disease, Parkinson's disease, AIDS-associated dementia and Down syndrome as well as for the treatment of schizophrenia and myoclonus (23). Following the importance and usefulness of dihydropyrano[c]chromene derivatives, numerous synthetic pathways have been described, including electrolysis (24) microwave and ultrasonic irradiation (25-26) by piperidine/pyridine in ethanol (27), $\mathrm{H}_{6} \mathrm{P}_{2} \mathrm{~W}_{18} \mathrm{O}_{62} \cdot 18 \mathrm{H}_{2} \mathrm{O}$, tetrabutylammonium bromide, copper oxide nanoparticles, sodium dodecyl sulfate (SDS), trisodium citrate, selectfluor chloride triethylbenzylammonuim DABCO in aqueous media (28-35). Tetramethylguanidinium trifluoroacetate (TMGT) (36), rare earth perfluorooctanoates (37), $\mathrm{Na}_{2} \mathrm{SeO}_{4}$ (38), $\mathrm{SiO}_{2}-\mathrm{Pr}-\mathrm{SO}_{3}$ (39), functionalized sulfonic acid silica (40), hexamethylenetetramine (41), $\mathrm{Fe}_{2} \mathrm{O}_{3}$ nanoparticles (42), the complexes of silica gel (43), Ru (II)(44), Urea (45), $\mathrm{NH}_{4} \mathrm{VO}_{3}$ (46), starch solution (47), grindstone chemistry (48), SBPPSP (49), MgO nanoparticle (50), ammonium acetate (51), 4-(dimethylamino)pyridine (DMAP) (52). Some synthetic catalysts of phosphate have also been reported in the literature for 3,4-dihydropyrano[c]chromenes synthesis; one found the Disodium hydrogen phosphate (53) and DHAP which has been described once as a homogeneous catalyst in the presence of ethanol-water (54). The majority of these methods use the expensive or homogenous catalysts that present certain disadvantages such as deactivation of the catalyst, difficult work and toxic effluents, not forgetting in some cases the low yields of the desired product, the long reaction time, and the most of them are synthetic and they require special efforts in their preparation. For these reasons, the development of a new and mild method that overcomes the drawbacks of previous procedures. In this context, this is the first time that phosphate fertilizers (MAP, DAP and 
TSP) are used directly as heterogeneous catalysts in their granule form for the synthesis of 3,4-dihydropyrano [c] chromene, in order to valorize one of the important natural resources in Morocco that is considered among the first countries producer of the natural phosphate.

The present work is oriented in particular on the direct application of phosphate monoammonium phosphate (MAP), di-ammonium phosphate (DAP) and triple super phosphate (TSP) as heterogeneous catalysts that they are already used in some researchers developed in our laboratory focused on synthesis in organic chemistry (55). Thus, we projected to the synthesis of 3,4-dihydropyrano[c]chromene in the presence of these heterogeneous catalysts, It was shown that they could be easily recovered and reused, as a consequence they can be considered among the most efficient catalysts in organic synthesis from the multicomponent reactions (MCRs) (56-57). The novelty of this study is the use of new catalysts, available in large quantities and inexpensive because Morocco is considered as a leader in the phosphate production. For this reason, this work is focused on the valorization of the fertilizer phosphate in the catalytic area. It is well known as reported before that these catalysts led to the desired products with excellent yields in short reaction times. The contribution of this work in the development of Moroccan natural resources for participating to economize of the cost of manipulation and energy of the reaction as well as to the development of green chemistry. In addition, the besides one of the strong point of these catalysts is that they are used as a heterogeneous catalyst in their natural shape without further preparation.

\section{MATERIALS AND METHODS}

The chemicals used in this work were purchased from Sigma-Aldrich Chemical Companies. The known products were identified by comparison of their melting points and their spectral data with those reported in the literature. Monitoring of the evolution of the reactions was carried out by TLC on silica gel SILG / UV 254 plates. The melting points were taken on a hot Kofler and are not corrected. ${ }^{1} \mathrm{H}$ NMR and ${ }^{13} \mathrm{C}$ NMR spectra were recorded on a 300 $\mathrm{MHz}$ Bruker spectrometer in DMSO-d6.

\section{General procedure for the synthesis of 3,4-dihydropyrano [c] chromene}

A mixture of malononitrile $(1 \mathrm{mmol})$, aromatic aldehyde $(1 \mathrm{mmol})$ and 4 -hydroxycoumarin ( $1 \mathrm{mmol}$ ) in ethanol $(1 \mathrm{~mL})$, in the presence of $0.01 \mathrm{~g}$ of catalyst, was brought to reflux, the reaction was monitored by TLC. After completion of the reaction, the reaction mixture was cooled to room temperature, the solid thus formed was collected by filtration, washed with ethanol and purified by recrystallization from hot ethanol to give pure products $\mathbf{4 a -}$ 
4f. The product obtained was characterized on the basis of their melting points reported in Table 5 and spectroscopic data that are given below and their comparison with the ones given in the literature show a good agreement.

2-Amino-4-phenyl-4,5-dihydro-5-oxopyrano[3,2-c]chromene-3-carbonitrile 4a:

${ }^{1} \mathrm{H}$ NMR (300 MHz, DMSO-d 6 , delta, ppm): $7.91(1 \mathrm{H}, \mathrm{d}, \mathrm{Ar}-\mathrm{H}), 7.70(1 \mathrm{H}, \mathrm{t}, \mathrm{Ar}-\mathrm{H}), 7.49$ $(1 \mathrm{H}, \mathrm{t}, \mathrm{Ar}-\mathrm{H}), 7.45(1 \mathrm{H}, \mathrm{d}, \mathrm{Ar}-\mathrm{H}), 7.42\left(2 \mathrm{H}, \mathrm{s}, \mathrm{NH}_{2}\right), 7.35-7.24(5 \mathrm{H}, \mathrm{m}, \mathrm{Ar}-\mathrm{H}), 4.45(1 \mathrm{H}$, $\mathrm{s}, \mathrm{CH}) .{ }^{13} \mathrm{C}$ NMR $\left(75 \mathrm{MHz}, \mathrm{DMSO}-\mathrm{d}_{6}\right): \delta 160,158.46,153.89,152.61,143.80,133.38$, $128.99,128.10,127.59,125.13,122.94,119.70,117.03,113.43,104.48,58.48$.

2-Amino-4-p-tolyl-4,5-dihydro-5-oxopyrano[3,2-c]chromene-3-carbonitrile 4b:

${ }^{1} \mathrm{H}$ NMR (300 MHz, DMSO-d6, delta, ppm): $7.91(1 \mathrm{H}, \mathrm{d}, \mathrm{Ar}-\mathrm{H}), 7.72(1 \mathrm{H}, \mathrm{t}, \mathrm{Ar}-\mathrm{H}), 7.50-$ $7.42(2 \mathrm{H}, \mathrm{m}, \mathrm{Ar}-\mathrm{H}), 7.38\left(2 \mathrm{H}, \mathrm{s}, \mathrm{NH}_{2}\right), 7.17-7.10(4 \mathrm{H}, \mathrm{m}, \mathrm{Ar}-\mathrm{H}), 4.40(1 \mathrm{H}, \mathrm{s}, \mathrm{CH}), 2.26$ $\left(3 \mathrm{H}, \mathrm{s}, \mathrm{CH}_{3}\right) .{ }^{13} \mathrm{C}$ NMR $\left(75 \mathrm{MHz}, \mathrm{DMSO}-\mathrm{d}_{6}\right): \delta 159.97,158.41,153.72,152.57,140.87$, $136.75,133.32,129.53,127.99,125.10,122.91,119.72,117,113.43,104.61,58.60$, 21.09.

2-Amino-4-(4-diméthylaminophenyl)-4,5-dihydro-5-oxopyrano[3,2-c]chromene-3carbonitrile 4c: ${ }^{1} \mathrm{H}$ NMR (300 MHz, DMSO- $\mathrm{d}_{6}$, delta, ppm): $7.83(1 \mathrm{H}, \mathrm{d}, \mathrm{Ar}-\mathrm{H}), 7.72(1 \mathrm{H}, \mathrm{t}$, ArH), $7.50-7.42(2 \mathrm{H}, \mathrm{m}, \mathrm{Ar}-\mathrm{H}), 7.19\left(2 \mathrm{H}, \mathrm{s}, \mathrm{NH}_{2}\right), 7.08-6.65(4 \mathrm{H}, \mathrm{m}, \mathrm{Ar}-\mathrm{H}), 4.33(1 \mathrm{H}, \mathrm{s}$, $\mathrm{CH}), 2.86\left(6 \mathrm{H}, \mathrm{s}, \mathrm{N}\left(\mathrm{CH}_{3}\right)_{2}\right) .{ }^{13} \mathrm{C}$ NMR $\left(75 \mathrm{MHz}, \mathrm{DMSO}-\mathrm{d}_{6}\right): \delta 159.97,158.44,154.88$, $152.54,134.04,131.41,128.63,125.05,122.89,119.73,116.96,113.56,105.22,59.27$.

2-Amino-4-(4-nitrophenyl)-4,5-dihydro-5-oxopyrano[3,2-c]chromene-3-carbonitrile 4d:

${ }^{1} \mathrm{H}$ NMR (300 MHz, DMSO-d6, delta, ppm): $8.17(1 \mathrm{H}, \mathrm{d}, \mathrm{Ar}-\mathrm{H}), 7.91(1 \mathrm{H}, \mathrm{d}, \mathrm{Ar}-\mathrm{H}), 7.77$ $(1 \mathrm{H}, \mathrm{t}, \mathrm{Ar}-\mathrm{H}), 7.74(1 \mathrm{H}, \mathrm{t}, \mathrm{Ar}-\mathrm{H}), 7.57\left(2 \mathrm{H}, \mathrm{s}, \mathrm{NH}_{2}\right), 7.55-7.46(4 \mathrm{H}, \mathrm{m}, \mathrm{Ar}-\mathrm{H}), 4.68(1 \mathrm{H}, \mathrm{s}$, $\mathrm{CH}) .{ }^{13} \mathrm{C}$ NMR $\left(75 \mathrm{MHz}, \mathrm{DMSO}-\mathrm{d}_{6}\right): \delta 160.05,158.52,154.43,152.75,151.23,147.09$, $133.66,129.65,125.23,124.20,123.06,119.35,117.11,113.38,103.28,57.24$.

2-Amino-4-(4-bromophenyl)-4,5-dihydro-5-oxopyrano[3,2-c]chromene-3-carbonitrile 4e: ${ }^{1} \mathrm{H}$ NMR $\left(300 \mathrm{MHz}, \mathrm{DMSO}-\mathrm{d}_{6}\right.$, delta, ppm): 7.93(1H,d, ArH), $7.73(1 \mathrm{H}, \mathrm{t}, \mathrm{Ar}-\mathrm{H}), 7.68(1 \mathrm{H}$, $\mathrm{t}, \mathrm{Ar}-\mathrm{H}), 7.52-7.48(3 \mathrm{H}, \mathrm{m}, \mathrm{Ar}-\mathrm{H}), 7.45(2 \mathrm{H}, \mathrm{s}, \mathrm{NH} 2), 7.26(2 \mathrm{H}, \mathrm{d}, \mathrm{Ar}-\mathrm{H}), 4.48(1 \mathrm{H}, \mathrm{s}, \mathrm{CH})$. ${ }^{13} \mathrm{C}$ NMR (75 MHz, DMSO-d6): $\delta 159.95,158.53,154.07,152.70,143.17,133.43,131.82$, $130.42,125.09,123.02,120.70,119.39,117,113.43,103.97,58.22$.

2-Amino-4-(4-chlorophenyl)-4,5-dihydro-5-oxopyrano[3,2-c]chromene-3-carbonitrile 4f: ${ }^{1} \mathrm{H}$ NMR (300 MHz, DMSO-d 6 , delta, ppm): $7.92(1 \mathrm{H}, \mathrm{d}, \mathrm{Ar}-\mathrm{H}), 7.71(1 \mathrm{H}, \mathrm{t}, \mathrm{Ar}-\mathrm{H}), 7.48$ $(1 \mathrm{H}, \mathrm{t}, \mathrm{Ar}-\mathrm{H}), 7.43(1 \mathrm{H}, \mathrm{d}, \mathrm{Ar}-\mathrm{H}), 7.40(2 \mathrm{H}, \mathrm{s}, \mathrm{NH} 2), 7.37-7.30(4 \mathrm{H}, \mathrm{m}, \mathrm{Ar}-\mathrm{H}), 4.50(1 \mathrm{H}$, 
$\mathrm{s}, \mathrm{CH}) .{ }^{13} \mathrm{C}$ NMR $\left(75 \mathrm{MHz}, \mathrm{DMSO}-\mathrm{d}_{6}\right): \delta 159.94,158.54,154.05,152.69,142.73,133.39$, $132.25,130.05,129.14,125.06,123,119.40,116.97,113.43,104.04,58.31$.

\section{RESULTS AND DISCUSSION}

In order to test the catalytic activity of the phosphate heterogeneous catalysts MAP, DAP, and TSP used herein, we have chosen the synthesis of 3,4-dihydropyrano[c]chromene, which is a condensation between an aromatic aldehyde, malononitrile, and 4hydroxycoumarin (MCR) (Scheme 1).<smiles>O=Cc1ccccc1</smiles>

1<smiles>N#CCC#N</smiles>

2<smiles>O=c1cc(O)c2ccccc2o1</smiles>

3

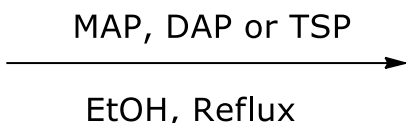

EtOH, Reflux<smiles>N#CC1=C(N)Oc2c(c(=O)oc3ccccc23)C1c1ccccc1</smiles>

$4 a$

Scheme 1. Synthesis of 3,4-dihydropyrano[c]chromene.

Table 1. Catalytic Test for the Synthesis of the 3,4-Dihydropyran[c]Chromene ${ }^{a}$.

\begin{tabular}{ccccc}
\hline Entry & Catalyst & $\begin{array}{c}\text { Amount of } \\
\text { catalyst }(\mathbf{g})\end{array}$ & Time & Yield (\%) \\
\hline 1 & - & 0 & $24 \mathrm{~h}$ & 25 \\
2 & MAP & 0.01 & $30 \mathrm{~min}$ & 86 \\
3 & DAP & 0.01 & $45 \mathrm{~min}$ & 82 \\
4 & TSP & 0.01 & $35 \mathrm{~min}$ & 82
\end{tabular}

aReaction conditions: Benzaldehyde (1 mmol), malononitrile $(1 \mathrm{mmol})$, 4-hydroxycoumarin (1 $\mathrm{mmol})$, EtOH ( $3 \mathrm{~mL}), 0.01 \mathrm{~g}$ of MAP, DAP and TSP, Reflux.

bIsolated yield.

First, the reaction was tested in the absence of the catalyst, when the experiment had started no product was observed, but after prolonged reaction time ( $24 \mathrm{~h}$ ), the desired product was obtained with a yield of $25 \%$, while the reaction in the presence of the catalysts MAP, DAP and TSP improve the reactivity and provide products with reasonable yields which were respectively 86,82 and $82 \%$. The reaction times are short as 30 min for the MAP, $45 \mathrm{~min}$ for the DAP and $35 \mathrm{~min}$ for the TSP. These results confirm that the used catalysts possess catalytic activity efficient for the synthesis of the 3,4dihydropyrano[c]chromene (Table 1 ).

In order to optimize the reaction conditions of the 3,4-dihydropyrano[c]chromene synthesis catalyzed by MAP, DAP, and TSP, it seems interesting for us to examine the effect 
of different parameters namely the of the reaction time, the amount of catalyst as well as the nature and volume of the solvent.

We have opted to examine the influence of the reaction time which is the fundamental parameter providing a straight effect on of the reaction yield. The yield of the desired product $4 \mathbf{a}$ was determined in function of the reaction time that was varied by a step of 5 min starting from 30, 45 and $35 \mathrm{~min}$, respectively for the MAP, DAP and TSP catalysts, these times are those obtained under the same conditions described previously ( (a) given after Table 1). The results of this study are presented in Figure 1.

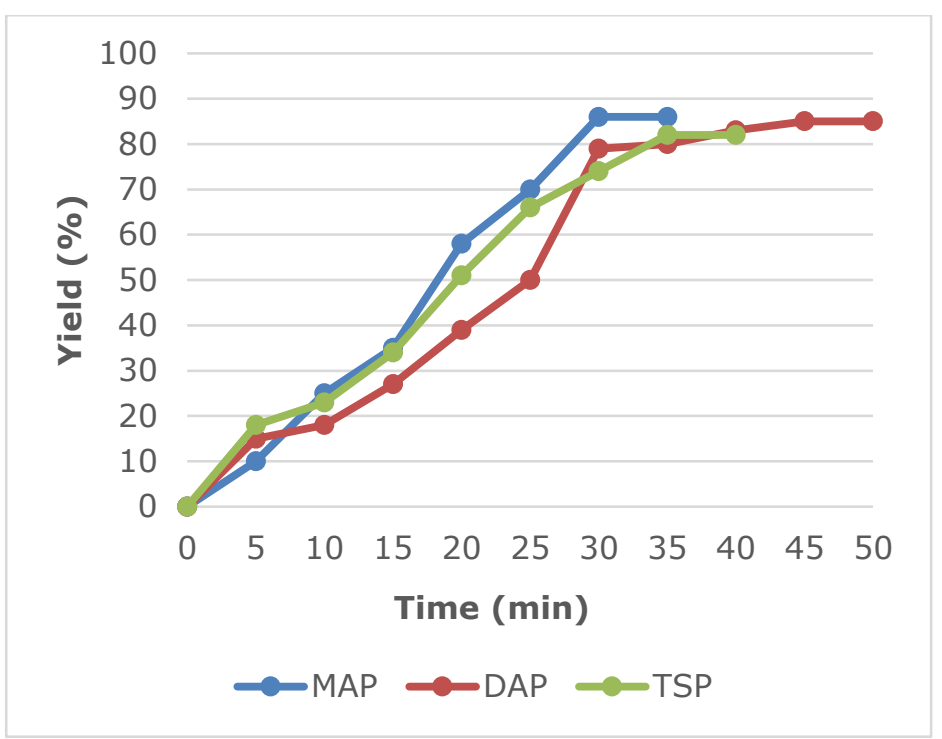

Figure 1. Time reaction optimization of the synthesis of 3,4-dihydropyran[c]chromene.

Figure 1 shows that the yield increases when the reaction time increases until the platform where the yield remains constant in function of time, indeed the yield of synthesis product reaches $86 \%$ after 30 min for the MAP. Whereas, both DAP and TSP catalysts give the same yield by $82 \%$ with 45 and 35 min as reaction times respectively.

After having optimized the reaction time, we consider useful to study the amount effect of the catalysts MAP, DAP and TSP used herein. For that, the amount of each catalyst has been varied from $0.002 \mathrm{~g}$ to $0.01 \mathrm{~g}$. The obtained yields are collected in Table 2. 
Table 2. The catalysts mass optimization for the synthesis of 3,4-dihydropyrano[c] chromene $e^{a}$.

\begin{tabular}{cccccccc}
\hline & $\begin{array}{c}\text { Amount of } \\
\text { catalyst }\end{array}$ & \multicolumn{3}{c}{ Time (min) } & \multicolumn{3}{c}{ Yield (\%) } \\
\cline { 3 - 8 } & $\mathbf{( g )}$ & MAP & DAP & TSP & MAP & DAP & TSP \\
\hline 1 & 0.002 & 30 & 45 & 35 & 80 & 86 & 87 \\
2 & 0.004 & 30 & 45 & 35 & 85 & 90 & 92 \\
3 & 0.006 & 30 & 45 & 35 & 93 & 87 & 88 \\
4 & 0.008 & 30 & 45 & 35 & 89 & 83 & 85 \\
5 & 0.01 & 30 & 45 & 35 & 86 & 82 & 82 \\
\hline
\end{tabular}

aReaction conditions: benzaldehyde $(1 \mathrm{mmol})$, malononitrile $(1 \mathrm{mmol})$, 4-hydroxycoumarin (1 $\mathrm{mmol})$, EtOH ( $3 \mathrm{~mL}),(\mathrm{xg})$ mass of MAP, DAP and TSP, Reflux.

bIsolated yield.

From the table above, it is noticeable that the amount of $0.006 \mathrm{~g}$ for the MAP and $0.004 \mathrm{~g}$ for both DAP and TSP catalysts are sufficient to provide excellent yields in case of the reaction leading to product $\mathbf{4 a}$. The obtained yields are 93, 90 and $92 \%$ for MAP, DAP and TSP, respectively. Beyond these amounts, the observation of a remarkable decrease in yields, parallel to the increase in the quantity of the catalyst, is justified by the dispersive effect of the reagent on the surface of the catalysts.

The influence of the solvent nature on the catalytic activity of MAP, DAP, and TSP was studied in case of the model reaction while maintaining the same optimized parameters, namely reaction time and catalyst amount, described previously. For this, solvents of different nature, protic polar $(\mathrm{EtOH}, \mathrm{MeOH})$, aprotic $\left(\mathrm{CH}_{3} \mathrm{CN}, \mathrm{THF}\right)$, as well as solvents of apolar nature (toluene, dioxane), were used, the reaction was also performed in absence of the solvent. Table 3 summarizes all the results obtained in this study.

Table 3. Reaction yield of the synthesis of 3,4-dihydropyrano[c]chromene a in presence of a different kind of solvent.

\begin{tabular}{cccccccc}
\hline & & \multicolumn{3}{c}{ Time $(\mathbf{m i n})$} & \multicolumn{3}{c}{ Yield (\%) } \\
\cline { 3 - 7 } Entry & Solvent & MAP & DAP & TSP & MAP & DAP & TSP \\
\hline 1 & Solvent-free & 30 & 45 & 35 & 78 & 74 & 74 \\
2 & $\mathrm{EtOH}$ & 30 & 45 & 35 & 93 & 90 & 92 \\
3 & $\mathrm{MeOH}$ & 30 & 45 & 35 & 75 & 77 & 83 \\
4 & $\mathrm{CH}_{3} \mathrm{CN}$ & 30 & 45 & 35 & 74 & 77 & 79 \\
5 & $\mathrm{THF}$ & 30 & 45 & 35 & 61 & 75 & 80 \\
6 & Dioxane & 30 & 45 & 35 & 63 & 60 & 77 \\
7 & Toluene & 30 & 45 & 35 & 59 & 55 & 70 \\
\hline
\end{tabular}

a Reaction conditions: Benzaldehyde (1 mmol), malononitrile (1 mmol), 4-hydroxycoumarin (1 $\mathrm{mmol})$, ( $3 \mathrm{~mL}$ ) of solvent, $0.006 \mathrm{~g}$ of MAP, $0.004 \mathrm{~g}$ of DAP and TSP, Reflux.

bIsolated yield.

The results given in Table 3 show that the reaction is clearly favored in protic polar solvents and more specifically in ethanol, this is available for the model reaction where the MAP, 
DAP, and TSP catalysts were applied, the product $\mathbf{4 a}$ is obtained with yields which are 93, 90 and $92 \%$ respectively. However, in the case of methanol it is noted that it allows obtaining the product with a lower yield than ethanol even though its dielectric constant is greater compared to the ethanol one, which may be explained by the fact that the methanol is more acidic than the ethanol, thus the $\mathrm{O}-\mathrm{H}$ bond is more polar in methanol than in ethanol. Therefore, the methanol tends to liberate the proton more easily, unlike to the ethanol which just allows the polarization of the reagents leading to the formation of the desired product $4 \mathrm{a}$ with a good yield. Moreover, the appropriate solvent for each organic synthesis depends on the nature of the reaction mixture. Therefore, the use of ethanol as a solvent facilitates the formation and the separation of the charges on the active sites of the reagents, indeed this process is caused by the electrostatic interaction involved between the atomic charge on the atom forming polar bond of the solvent with the active atomic center which possesses the opposite sign of charge, in the reagent, this interaction makes easy the formation of the final product $4 a$.

As regards on the aprotic polar solvents $\left(\mathrm{CH}_{3} \mathrm{CN}, \mathrm{THF}\right)$ and nonpolar (toluene, dioxane), used in this part of our study, one can notice that the yield obtained in presence of each solvent is lower than that obtained in ethanol. One can deduce that the ethanol is the appropriate solvent allowing to obtain the desired product with excellent yields.

The volume of the solvent can also be a determining factor that can influence the yield of the 3,4-dihydropyrano[c]chromene synthesis, for this reason, it would be interesting to study the volume effect that was carried out by taking into account of the optimized parameters obtained previously, for this, the volume of ethanol was decreased from 3 to $1 \mathrm{ml}$, and Table 4 summarizes the obtained results.

Table 4. Optimization of the ethanol volume on the synthesis of 3,4dihydropyrano[c]chromene ${ }^{\text {a }}$.

\begin{tabular}{cccccccc}
\hline \multirow{2}{*}{ Entry } & $\begin{array}{c}\text { Volume of } \\
\text { ethanol }\end{array}$ & \multicolumn{3}{c}{ Time (min) } & \multicolumn{3}{c}{ Yield (\%) } \\
\cline { 3 - 7 } & Solvent-free & 30 & 45 & 35 & 78 & 74 & 74 \\
\hline 1 & $1 \mathrm{~mL}$ & 30 & 45 & 35 & 95 & 92 & 93 \\
2 & $2 \mathrm{~mL}$ & 30 & 45 & 35 & 94 & 91 & 93 \\
3 & $3 \mathrm{~mL}$ & 30 & 45 & 35 & 93 & 90 & 92 \\
4 & SAP & DAP & TSP & MAP & DAP & TSP
\end{tabular}

a Reaction conditions: benzaldehyde (1 mmol), malononitrile (1 mmol), 4-hydroxycoumarine (1 $\mathrm{mmol}),(\mathrm{x} \mathrm{mL})$ of EtOH, $0.006 \mathrm{~g}$ of MAP, $0.004 \mathrm{~g}$ of DAP and TSP, reflux.

bIsolated yield.

From Table 4, it can be shown that $1 \mathrm{~mL}$ of ethanol appears to be the sufficient volume to achieve a yield of 95,92 and $93 \%$ for the model reaction catalyzed by the MAP, DAP and 
TSP respectively, whereas beyond $1 \mathrm{~mL}$ a decrease in yield has been observed, this is due the dispersion phenomenon of the reagents on the catalyst surface.

One of the most important factors that determine the efficiency of the catalytic activity of the catalyst is its ability to be reused for several times and its reliability to give a good reaction yield for each reuse, this allows to ensure sustainable chemistry. In this context the recovery and study of the reuse of MAP, DAP and TSP catalysts were carried out under the optimum reaction conditions already determined, the catalysts recovered by simple filtration and reused in a second reaction involving the same reagents and under the same operating conditions. This operation was repeated for four times, Figure 2 presents the results obtained.

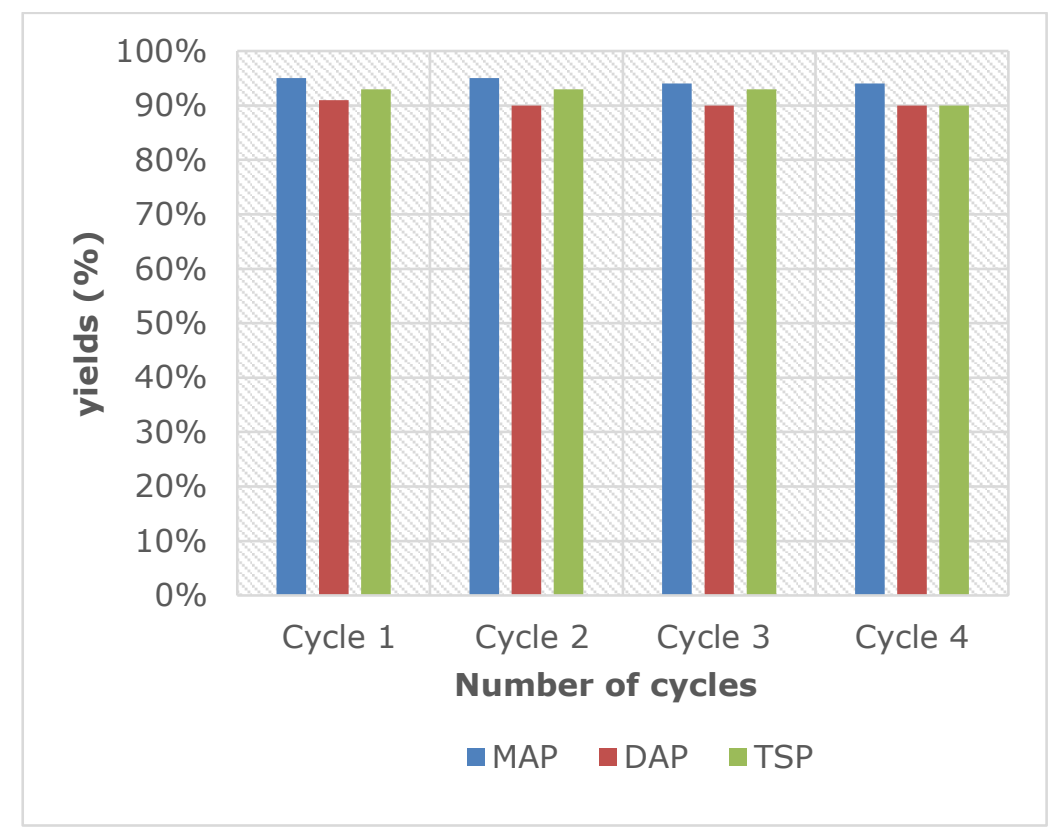

Figure 2. Reusability of the MAP, DAP, and TSP catalysts in case of the synthesis of 3,4dihydropyrano [c] chromene.

The results clearly show that MAP, DAP and TSP catalysts can be reused several times without significant loss of their catalytic activities even after 4 cycles of application. After optimization of the reactional conditions for the synthesis of a product (4a 3,4dihydropyrano[c]chromene), a generalization study of the reaction was carried out in order to synthesize other derivatives belonging to the same family of 3,4-dihydropyrano [c] chromene. These derivatives have been synthesized from various aromatic aldehydes, malononitrile and 4-hydroxycoumarin under the optimum operating conditions already determined, the obtained yields are given in Table 5. 
<smiles>[R]c1ccc(C=O)cc1</smiles>

1<smiles>N#CCC#N</smiles>

2<smiles>O=c1cc(O)c2ccccc2o1</smiles>

3

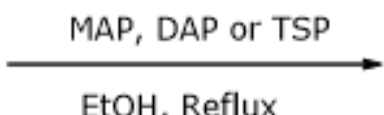

EtOH, Reflux<smiles>[R]c1ccc(C2C(C#N)=C(N)Oc3c2c(=O)oc2ccccc32)cc1</smiles>

4a-4f

Scheme 2. Synthesis of 3,4-dihydropyrano[c]chromene derivatives.

Table 5. Reaction times and yields of the synthesis reactions of 3,4-dihydropyrano[c] chromene ${ }^{a}$

\begin{tabular}{cccccccccc}
\hline \multirow{2}{*}{ Entry } & \multirow{2}{*}{$\mathbf{R}$} & \multicolumn{3}{c}{ Time (min) } & \multicolumn{3}{c}{ Yield (\%) $\mathbf{b}^{\mathbf{b}}$} & \multicolumn{2}{c}{ Mp $\left({ }^{\circ} \mathbf{C}\right)$} \\
\cline { 3 - 9 } & & MAP & DAP & TSP & MAP & DAP & TSP & Found & Reported \\
\hline $4 \mathrm{a}$ & $\mathrm{H}$ & 30 & 45 & 35 & 95 & 92 & 93 & $256-258$ & $256-258(58)$ \\
$4 \mathrm{~b}$ & $\mathrm{CH}_{3}$ & 30 & 30 & 35 & 88 & 80 & 81 & $251-253$ & $250-252(32)$ \\
$4 \mathrm{c}$ & $\left(\mathrm{CH}_{3}\right) \mathrm{N}$ & 45 & 45 & 45 & 97 & 87 & 94 & $>260$ & $266-268(32)$ \\
$4 \mathrm{~d}$ & $\mathrm{NO}_{2}$ & 15 & 15 & 15 & 98 & 85 & 84 & $258-260$ & $258-260(58)$ \\
$4 \mathrm{e}$ & $\mathrm{Br}$ & 15 & 15 & 15 & 84 & 83 & 87 & $248-250$ & $247-249(58)$ \\
$4 \mathrm{f}$ & $\mathrm{Cl}$ & 15 & 15 & 15 & 77 & 79 & 85 & $256-258$ & $258-260(32)$ \\
\hline
\end{tabular}

aReaction conditions: aromatic aldehyde ( $1 \mathrm{mmol})$, malononitrile (1 mmol), 4- hydroxycoumarin (1 $\mathrm{mmol}),(1 \mathrm{~mL})$ ethanol, $0.006 \mathrm{~g}$ of MAP, $0.004 \mathrm{~g}$ of DAP and TSP, reflux.

bIsolated yield.

The yields of desired products presented in Table 5 remains better regardless of the nature of the group, used as a substituent on the aromatic aldehyde, that is electron attractor in case of $\mathrm{NO}_{2}$ or electron donor in cases of $\mathrm{CH}_{3}, \mathrm{~N}\left(\mathrm{CH}_{3}\right)_{2}, \mathrm{Br}$ and $\mathrm{Cl}$ groups. The best-obtained yield is $98 \%$ for the entry $\mathbf{4 d}$ when the MAP catalyst is used while it is by $92 \%$ for entry 4a using DAP catalyst and it is $94 \%$ for entry $4 \mathrm{c}$ using TSP as a catalyst. Whereas the reaction times vary between $15 \mathrm{~min}$ and $45 \mathrm{~min}$ for the six synthesis reactions in presence of MAP, DAP and TSP catalysts used in this study.

To understand the interaction involved, between the catalyst and the reagents as well as between the solvent and the reagents, during the reaction process, the following mechanism is proposed to describe the condensation of an aromatic aldehyde, malononitrile and 4-hydroxycoumarin, using MAP catalyst and EtOH as solvent, for the synthesis of 2,3-dihydroquinazolin-4 (1H)-One (Scheme 3 ). 

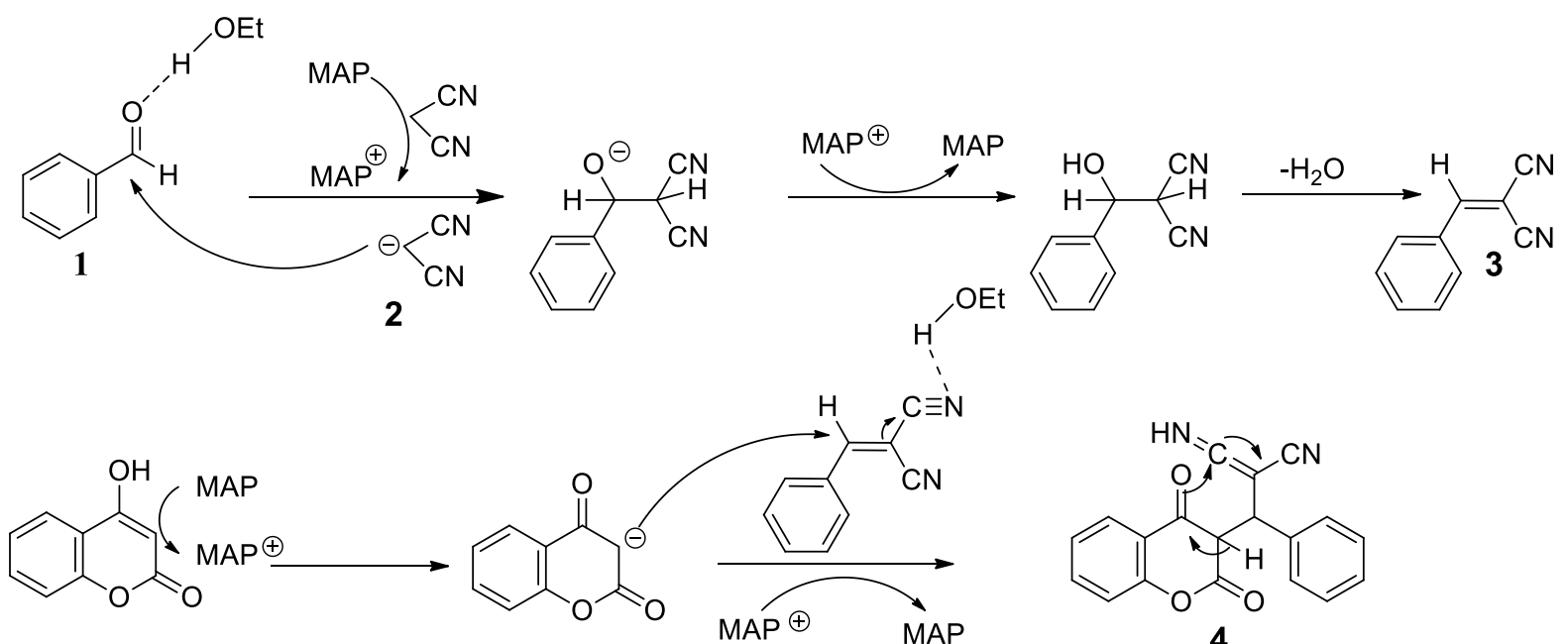<smiles></smiles>

6
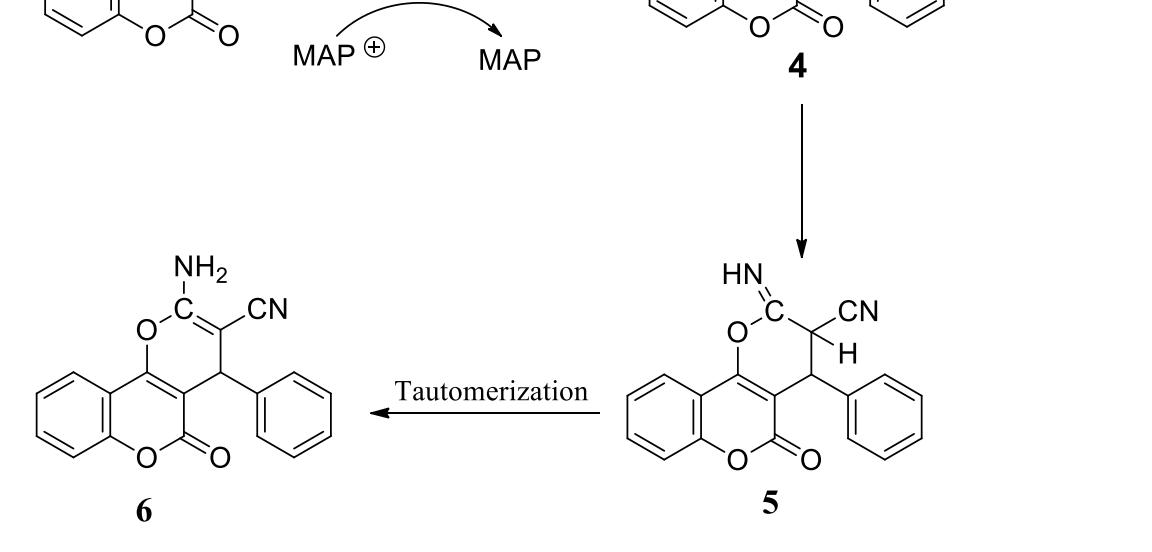

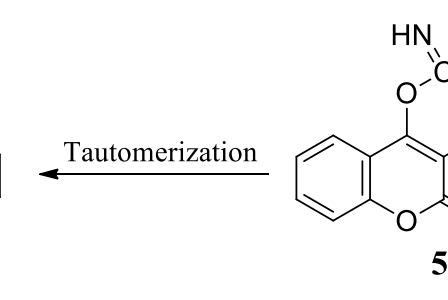

Scheme 3. A plausible mechanism (catalyst and solvent) for the formation of 3,4Dihydropyrano[c]Chromene.

Scheme 3 shows the proposed mechanism for the synthesis of 3,4 Dihydropyrano [c] chromene, firstly the condensation of knoevenagal between benzaldehyde $\mathbf{1}$ and malononitrile $\mathbf{2}$ in the presence of MAP (proposed as an ampholyte catalyst, in this mechanism plays the role of a base), which removes the proton from the malononitrile, and the ethanol which allows activation of the carbonyl group, followed by dehydration to produce the 2-benzylidenemalononitrile 3, And then, the nucleophilic addition of 4hydroxycoumarin at intermediate 3 , followed by intramolecular cyclization 4 and tautomerization for formation of corresponding product 6 .

In order to conclude about the effectiveness of MAP, DAP and TSP catalysts used herein, Table 6 collect the results of this work and some data from the literature concerning the same synthesis reaction and using another type of catalysts. 
Table 6. Comparative table of the reaction conditions for the synthesis of 3, 4dihydropyrano[c]chromene

\begin{tabular}{|c|c|c|c|c|c|c|c|}
\hline Entry & Catalyst & Catalyst amount & Solvent & $\mathbf{T}\left({ }^{\circ} \mathrm{C}\right)$ & time & $\begin{array}{l}\text { Yield } \\
(\%)\end{array}$ & Ref \\
\hline 1 & $\mathrm{Al}_{2} \mathrm{O}_{3}$ & $10 \mathrm{~mol} \%$ & Ethanol & Reflux & $2 \mathrm{~h}$ & 71 & (39) \\
\hline 2 & SDS & $20 \mathrm{~mol} \%$ & Water & Reflux & $2.5 \mathrm{~h}$ & 88 & (32) \\
\hline 3 & $\mathrm{RuBr}_{2}\left(\mathrm{PPh}_{3}\right)_{4}$ & $5 \mathrm{~mol} \%$ & Water & Reflux & $60 \mathrm{~min}$ & Trace & (44) \\
\hline 4 & $\mathrm{RuBr}_{2}\left(\mathrm{PPh}_{3}\right)_{4}$ & $5 \mathrm{~mol} \%$ & Ethanol & Reflux & $45 \mathrm{~min}$ & 45 & (44) \\
\hline 5 & Silica gel & 300 wt $\%$ & Ethanol & 25 & $4 \mathrm{~h}$ & 95 & (43) \\
\hline 6 & TEBA & $0.15 \mathrm{~g}$ & Water & Reflux & $10 \mathrm{~h}$ & 96 & (35) \\
\hline 7 & DBSA & $25 \mathrm{~mol} \%$ & Water & 90 & $4 \mathrm{~h}$ & 90 & (59) \\
\hline 8 & $\mathrm{Na}_{2} \mathrm{HPO}_{4}$ & $10 \mathrm{~mol} \%$ & $\mathrm{H}_{2} \mathrm{O}: \mathrm{EtOH}$ & Reflux & $10 \mathrm{~min}$ & 93 & (53) \\
\hline 9 & Piperidine & $10 \mathrm{~mol} \%$ & Ethanol & 25 & $30 \mathrm{~min}$ & 90 & (60) \\
\hline 10 & OBS & $50 \mathrm{~mol} \%$ & Solvent-free & 120 & $50 \mathrm{~min}$ & 85 & (61) \\
\hline 11 & $\mathrm{NH}_{4} \mathrm{OAc}$ & $15 \mathrm{~mol} \%$ & Ethanol & Reflux & $3 \min$ & 94 & (51) \\
\hline 12 & EDTA-4Na & $2 \mathrm{~mol} \%$ & $\mathrm{H}_{2} \mathrm{O}: \mathrm{EtOH}$ & 50 & $20 \mathrm{~min}$ & 91 & $(62)$ \\
\hline 13 & SBS & $10 \mathrm{~mol} \%$ & $\mathrm{H}_{2} \mathrm{O}: \mathrm{EtOH}$ & Reflux & $23 \mathrm{~min}$ & 89 & (63) \\
\hline 14 & MAP & $0.006 \mathrm{~g} / 2.5 \mathrm{~mol} \%$ & Ethanol & Reflux & $30 \mathrm{~min}$ & 95 & this work \\
\hline 15 & DAP & $0.004 \mathrm{~g} / 3.1 \mathrm{~mol} \%$ & Ethanol & Reflux & $45 \mathrm{~min}$ & 92 & this work \\
\hline 16 & TSP & $0.004 \mathrm{~g} / 1.7 \mathrm{~mol} \%$ & Ethanol & Reflux & $35 \mathrm{~min}$ & 93 & this work \\
\hline
\end{tabular}

Recently several works have been developed concerning the use of different kinds of catalyst for the synthesis studied herein. From the table 6, it can be seen that the catalysts MAP, DAP and TSP show interesting catalytic activities for the 3,4dihydropyrano[c]chromene synthesis, they lead high yields of the desired products in short reaction times even with smaller amounts of the catalyst compared to the that given in the literature. Nevertheless, some of these catalysts have a shorter reaction time and good yields compared to the results obtained in this work but have certain drawbacks as NH4OAc which is a homogeneous catalyst, piperidine which is a corrosive product and EDTA-4Na is a synthetic catalyst. To sum up, the catalysts used herein present several advantages, they resent interesting catalytic activities and they can be reused for at least 4 times.

\section{CONCLUSION}

To sum up, six 3, 4-dihydropyrano[c]chromenes have been successfully synthesized, using MAP, DAP and TSP phosphate fertilizers as heterogeneous catalysts which are available, inexpensive, non-toxic, and recyclable. The reactional conditions optimized in this work, namely, reaction time, catalyst amount, solvent nature and its volume, show that method has been characterized by simplicity of operation by reducing the cost of handling for organic synthesis, soft working conditions, short reaction times, excellent yields, and respect to the environment.

\section{REFERENCES}

1. Anastas PT, Kirchhoff MM. Origins, Current Status, and Future Challenges of Green Chemistry $†$. Acc Chem Res. 2002;35(9):686-94. 
2. Clark JH. Green chemistry: challenges and opportunities. Green Chem. 1999;1(1):1-8.

3. R S. Catalysis and Pollution Prevention. Chemistry \& Industry. 1997; 1:12-15.

4. Abba MO, Gonzalez-DelaCruz VM, Colón G, Sebti S, Caballero A. In situ XAS study of an improved natural phosphate catalyst for hydrogen production by reforming of methane. Appl Catal B Environ. 2014 ; 150-151 :459-65.

5. Hassine A, Sebti S, Solhy A, Zahouily M, Len C, Hedhili MN, et al. Palladium supported on natural phosphate: Catalyst for Suzuki coupling reactions in water. Appl Catal Gen. 2013 ; 450 :13-8.

6. Dakkach M, Atlamsani A, Sebti S. Le phosphate naturel modifié au vanadium : un nouveau catalyseur pour l'oxydation des cycloalcanones et des a-cétols en présence de l'oxygène moléculaire. Comptes Rendus Chim. 2012;15(6):482-92.

7. Zahouily M, Salah M, Bahlaouane B, Rayadh A, Houmam A, Hamed EA, et al. Solid catalysts for the production of fine chemicals: the use of natural phosphate alone and doped base catalysts for the synthesis of unsaturated arylsulfones. Tetrahedron. 2004;60(7):1631-5.

8. Zahouily M, Bahlaouan B, Rayadh A, Sebti S. Natural phosphate and potassium fluoride doped natural phosphate: efficient catalysts for the construction of a carbon-nitrogen bond. Tetrahedron Lett. $2004 ; 45(21): 4135-8$.

9. Alahiane A, Rochdi A, Taourirte M, Redwane N, Sebti S, Lazrek H. Natural phosphate as Lewis acid catalyst: a simple and convenient method for acyclonucleoside synthesis. Tetrahedron Lett. 2001;42(21):3579-81.

10. Wen C, Cui Y, Chen X, Zong B, Dai W-L. Reaction temperature controlled selective hydrogenation of dimethyl oxalate to methyl glycolate and ethylene glycol over copperhydroxyapatite catalysts. Appl Catal B Environ. 2015; 162:483-93.

11. Maleki B, Barat Nam Chalaki S, Sedigh Ashrafi S, Rezaee Seresht E, Moeinpour F, Khojastehnezhad A, et al. Caesium carbonate supported on hydroxyapatite-encapsulated Ni $0.5 \mathrm{Zn}$ 0.5 Fe 204 nanocrystallites as a novel magnetically basic catalyst for the one-pot synthesis of pyrazolo[1,2-b] phthalazine-5,10-diones: Nanocatalyst for synthesis of pyrazolo[1,2-b] phthalazine-5,10-diones. Appl Organomet Chem. 2015;29(5):290-5.

12. Peeters A, Claes L, Geukens I, Stassen I, De Vos D. Alcohol amination with heterogeneous ruthenium hydroxyapatite catalysts. Appl Catal Gen. 2014; 469:191-7.

13. Razavi N, Akhlaghinia B. Hydroxyapatite nanoparticles (HAP NPs): a green and efficient heterogeneous catalyst for three-component one-pot synthesis of 2,3-dihydroquinazolin-4(1H)-one derivatives in aqueous media. New J Chem. 2016;40(1):447-57.

14. El Badaoui H, Bazi F, Tahir R, Lazrek HB, Sebti S. Synthesis of 3,4-dihydropyrimidin-2-ones catalysed by fluorapatite doped with metal halides. Catal Commun. 2005;6(7):455-8.

15. Mulla SAR, Chavan SS, Pathan MY, Inamdar SM, Shaikh TMY. Ligand-, base-, co-catalyst-free copper fluorapatite (CuFAP) as a versatile, ecofriendly, heterogeneous and reusable catalyst for an efficient homocoupling of arylboronic acid at ambient reaction conditions. RSC Adv. $2015 ; 5(31): 24675-80$.

16. Mulla SAR, Inamdar SM, Pathan MY, Chavan SS. Ligand free, highly efficient synthesis of diaryl ether over copper fluorapatite as heterogeneous reusable catalyst. Tetrahedron Lett. $2012 ; 53(14): 1826-9$.

17. Geen G, Evans J, Vong A. Pyrans and Their Benzo Derivatives Synthesis: In Comprehensive Heterocyclic Chemistry II; Oxford, UK: Pergamon Press; 1995.

18. Jain S, Rajguru D, Keshwal BS, Acharya AD. Solvent-Free Green and Efficient One-Pot Synthesis of Dihydropyrano[3,2-c]chromene Derivatives. ISRN Org Chem. 2013; 2013:1-5. 
19. Bonsignore L, Loy G, Secci D, Calignano A. Synthesis and pharmacological activity of 2-oxo(2H) 1-benzopyran-3-carboxamide derivatives. Eur J Med Chem. 1993;28(6):517-20.

20. Kostova I. New lanthanide complexes of 4-methyl-7-hydroxycoumarin and their pharmacological activity. Eur J Med Chem. 2001;36(4):339-47.

21. Chohan ZH, Shaikh AU, Rauf A, Supuran CT. Antibacterial, antifungal and cytotoxic properties of novel N-substituted sulfonamides from 4-hydroxycoumarin. J Enzyme Inhib Med Chem. $2006 ; 21(6): 741-8$.

22. Zhao H, Neamati N, Hong H, Mazumder A, Wang S, Sunder S, et al. Coumarin-Based Inhibitors of HIV Integrase 1. J Med Chem. 1997;40(2):242-9.

23. Khoobi M, Ma'mani L, Rezazadeh F, Zareie Z, Foroumadi A, Ramazani A, et al. One-pot synthesis of $4 \mathrm{H}$-benzo[b]pyrans and dihydropyrano[c]chromenes using inorganic-organic hybrid magnetic nanocatalyst in water. J Mol Catal Chem. 2012; 359:74-80.

24. Fotouhi L, Heravi MM, Fatehi A, Bakhtiari K. Electrogenerated base-promoted synthesis of tetrahydrobenzo[b]pyran derivatives. Tetrahedron Lett. juill 2007;48(31):5379-81.

25. Kidwai M, Saxena S. Convenient Preparation of Pyrano Benzopyranes in Aqueous Media. Synth Commun. 2006;36(18):2737-42.

26. Tu S-J, Jiang H, Zhuang Q-Y, Miao C-B, Shi D, Wang X-S, et al. One-pot synthesis of 2-amimo3-cyano-4-aryl-7,7-dimethyl-5-oxo-5,6,7,8-tetrahydro-4H-benzo[b]pyran under ultrasonic irradiation without catalyst. Chin J Org Chem. 2003; 23:488-90.

27. Shaker RM. Synthesis and reactions of some new 4H-pyrano[3,2-c] benzopyran-5-one derivatives and their potential biological activities. Pharm. 1996;51(3):148-51.

28. Heravi MM, Jani BA, Derikvand F, Bamoharram FF, Oskooie HA. Three components, one-pot synthesis of dihydropyrano[3,2-c] chromene derivatives in the presence of H6P2W18062.18H2O as a green and recyclable catalyst. Catal Commun. 2008;10(3):272-5.

29. Khurana JM, Kumar S. Tetrabutylammonium bromide (TBAB): a neutral and efficient catalyst for the synthesis of biscoumarin and 3,4-dihydropyrano[c]chromene derivatives in water and solvent-free conditions. Tetrahedron Lett. 2009;50(28):4125-7.

30. Mehrabi H, Kazemi-Mireki M. CuO nanoparticles: An efficient and recyclable nanocatalyst for the rapid and green synthesis of 3,4-dihydropyrano[c]chromenes. Chin Chem Lett. $2011 ; 22(12): 1419-22$

31. Zheng J, Li Y-Q. One-pot synthesis of tetrahydrobenzo[b]pyran and dihydropyrano[c]chromene derivatives in aqueous media by using trisodium citrate as a green catalyst. Arch Appl Sci Res. $2011 ; 3$.

32. Mehrabi $H$, Abusaidi $H$. Synthesis of biscoumarin and 3,4-dihydropyrano[c]chromene derivatives catalysed by sodium dodecyl sulfate (SDS) in neat water. J Iran Chem Soc. $2010 ; 7(4): 890-4$.

33. Heravi MM, Zakeri M, Mohammadi N. Morpholine Catalyzed One-pot Multicomponent Synthesis of Compounds Containing Chromene Core in Water. Chin J Chem. 2011;29(6):1163-6.

34. Ranjbar-Karimi R, Hashemi-Uderji S, Mousavi M. Selectfluor promoted environmental-friendly synthesis of $2 \mathrm{H}$-chromen-2-one derivatives under various reaction conditions. Journal of the Iranian Chemical Society. 2011;8(1):193-197.

35. Shi D, Wang J, Zhuang Q-Y, Wang X-S. Three-component one-pot synthesis of 1,6-dioxa-5oxo-1,4,5,6- tetrahydrophenanthrene derivatives in aqueous media. Chin J Org Chem. 2006; 26:643-7.

36. Shaabani A, Samadi S, Badri Z, Rahmati A. Ionic Liquid Promoted Efficient and Rapid One-pot Synthesis of Pyran Annulated Heterocyclic Systems. Catal Lett. 2005;104(1-2):39-43. 
37. Wang L-M, Shao J-H, Tian H, Wang Y-H, Liu B. Rare earth perfluorooctanoate [RE(PFO)3] catalyzed one-pot synthesis of benzopyran derivatives. J Fluor Chem. 2006;127(1):97-100.

38. Hekmatshoar R, Majedi S, Bakhtiari K. Sodium selenate catalyzed simple and efficient synthesis of tetrahydro benzo[b]pyran derivatives. Catal Commun. 2008;9(2):307-10.

39. Mohammadi Ziarani G, Badiei A, Azizi M, Zarabadi P. Synthesis of 3,4-

Dihydropyrano[c]Chromene Derivatives Using Sulfonic Acid Functionalized Silica (SiO2PrSO3H). Iran J Chem Chem Eng IJCCE. 2011;30(2):59-65.

40. Ziarani GM, Abbasi A, Badiei A, Aslani Z. An Efficient Synthesis of Tetrahydrobenzo[ $b$ ]pyran Derivatives Using Sulfonic Acid Functionalized Silica as an Efficient Catalyst. E-J Chem. $2011 ; 8(1): 293-9$.

41. Wang H-J, Lu J, Zhang Z-H. Highly efficient three-component, one-pot synthesis of dihydropyrano[3,2-c] chromene derivatives. Monatshefte Für Chem - Chem Mon. 2010;141(10):1107-12.

42. Nagabhushana H, Sandeep Saundalkar S, Muralidhar L, Nagabhushana BM, Girija CR, Nagaraja D, et al. a-Fe2O3 nanoparticles: An efficient, inexpensive catalyst for the one-pot preparation of 3,4-dihydropyrano[c]chromenes. Chin Chem Lett. 2011;22(2):143-6.

43. Prasanna TSR, Raju KM. Silica Gel Promoted Mild, Efficient and Inexpensive Protocol for the Preparation of 3,4-dihydropyrano[c]chromenes. J Korean Chem Soc. 20 août 2011;55(4):662-5.

44. Tabatabaeian K, Heidari H, Mamaghani M, Mahmoodi NO. Ru(II) complexes bearing tertiary phosphine ligands: a novel and efficient homogeneous catalyst for one-pot synthesis of dihydropyrano[3,2-c] chromene and tetrahydrobenzo[b]pyran derivatives: Ru(II)-catalyzed synthesis of dihydropyrano[c]chromene derivatives. Appl Organomet Chem. 2012;26(2):56-61.

45. Brahmachari G, Banerjee B. Facile and One-Pot Access to Diverse and Densely Functionalized 2-Amino-3-cyano-4 H -pyrans and Pyran-Annulated Heterocyclic Scaffolds via an Eco-Friendly Multicomponent Reaction at Room Temperature Using Urea as a Novel Organo-Catalyst. ACS Sustain Chem Eng. 3 mars 2014;2(3):411-22.

46. Shitole BV, Shitole NV, Shingare MS, Kakde GK. An efficient one pot three-component synthesis of dihydropyrano[3,2-c] chromenes using ammonium metavanadate as catalyst. Curr Chem Lett. 2016;137-44.

47. Hazeri N, Maghsoodlou MT, Mir F, Kangani M, Saravani H, Molashahi E. An efficient one-pot three-component synthesis of tetrahydrobenzo[b]pyran and 3,4-dihydropyrano[c]chromene derivatives using starch solution as catalyst. Chin J Catal. 2014;35(3):391-5.

48. Patel DS, Avalani JR, Raval DK. One-pot solvent-free rapid and green synthesis of 3,4dihydropyrano[c]chromenes using grindstone chemistry. J Saudi Chem Soc. 2016;20:S401-5.

49. Niknam K, Jamali A. Silica-Bonded N-Propylpiperazine Sodium n-Propionate as Recyclable Basic Catalyst for Synthesis of 3,4-Dihydropyrano[c]chromene Derivatives and Biscoumarins. Chin ] Catal. 2012;33(11-12):1840-9.

50. Safaei-Ghomi J, Eshteghal F, Ghasemzadeh MA. Solvent-free synthesis of dihydropyrano [3,2c]chromene and biscoumarin derivatives using magnesium oxide nanoparticles as a recyclable catalyst. Acta Chim Slov. 2014;61(4):703-8.

51. Kanakaraju S, Prasanna B, Basavoju S, Chandramouli GVP. Ammonium acetate catalyzed an efficient one-pot three component synthesis of pyrano[3,2- c ]chromene derivatives. Arab ] Chem. 2017;10:S2705-13.

52. Khan AT, Lal M, Ali S, Khan MM. One-pot three-component reaction for the synthesis of pyran annulated heterocyclic compounds using DMAP as a catalyst. Tetrahedron Lett. 2011;52(41):5327-32. 
53. Shitole NV, Shitole BV, Kakde GK. Disodium Phosphate: A Highly Efficient Catalyst for One-Pot Synthesis of Substituted 3,4-Dihydropyrano[3,2-C]Chromenes. Orbital - Electron J Chem. 2017;9(3):131-4.

54. Abdolmohammadi S, Balalaie S. Novel and efficient catalysts for the one-pot synthesis of 3,4dihydropyrano[c]chromene derivatives in aqueous media. Tetrahedron Lett. avr 2007;48(18):3299-303.

55. Bahammou I, Esaady A, Boukhris S, Ghailane R, Habbadi N, Hassikou A, et al. Direct use of mineral fertilizers MAP, DAP, and TSP as heterogeneous catalysts in organic reactions. Mediterr J Chem. 2016;5(6):615-23.

56. Sibous S, Ghailane T, Houda S, Ghailane R, Boukhris S, Souizi A. Green and efficient method for the synthesis of 1,5-benzodiazipines using phosphate fertilizers as catalysts under free solvent. Mediterr J Chem. 2017;6(3):53-9.

57. Sibous S, Boukhris S, Ghailane R, Habbadi N, Hassikou A, Souizi A. Easy synthesis of 3,4dihydropyrimidin -2-(1H)-ones using phosphate fertilizers MAP, DAP AND TSP as efficient catalysts. J Turk Chem Soc Sect Chem. 2017; 4(2): 477-88.

58. Sheikhhosseini E, Sattaei Mokhtari T, Faryabi M, Rafiepour A, Soltaninejad S. Iron Ore Pellet, A Natural and Reusable Catalyst for Synthesis of Pyrano[2,3-d] pyrimidine and Dihydropyrano[c]chromene Derivatives in Aqueous Media. Iran J Chem Chem Eng IJCCE. 2016;35(1):43-50.

59. Sheikhhosseini E, Ghazanfari D, Nezamabadi V. A new method for synthesis of tetrahydrobenzo[b]pyrans and dihydropyrano[c]chromenes using p-dodecylbenzenesulfonic acid as catalyst in water. Iran J Catal. 2013;3(4):197-201.

60. Irani, S, Maghsoodlou, MT, Hazeri, Nourallah. Piperidine, an efficient base catalyst for the onepot synthesis of 3,4-dihydropyrano[3,2-c]chromene derivatives. NISCAIR-CSIR,. 2017;649-55

61. Maleki B. Green Synthesis of bis -Coumarin and Dihydropyrano[3,2-c]chromene Derivatives Catalyzed by o-Benzenedisulfonimide. Org Prep Proced Int. 2016;48(3):303-18.

62. Chen L, Lin J, Chen B, Zhao L. Sodium ethylene diamine tetraacetate catalyzed synthesis of chromene derivatives via multi-component reactions at low catalyst loading. Res Chem Intermed. 2017;43(11):6691-700.

63. Abaszadeh M, Seifi M. Three-Component Synthesis of Mono and Bis 4,5-Dihydropyrano[3,2C]Chromenes and 4,5- Dihydropyran[4,3-B]Pyrans Catalyzed by Sodium Benzenesulfinates as a Green Organocatalyst. Acta Chem Iasi. 2017; 25(1):38 -50 